\title{
Liver transplantation as curative approach for advanced hepatocellular carcinoma: is it justified?
}

\author{
Aiman Obed • Tung-Yu Tsui • \\ Andreas A. Schnitzbauer • Manal Obed • \\ Hans J. Schlitt • Heinz Becker • Thomas Lorf
}

Received: 28 May 2007 / Accepted: 6 November 2007 / Published online: 28 November 2007

(C) Springer-Verlag 2007

\begin{abstract}
Backgrounds Liver transplantation is considered as one of therapeutic approaches to hepatocellular carcinoma (HCC). The present study aims to evaluate the efficacy of various therapeutic options for HCC.

Materials and methods One hundred twenty patients with known HCC in various tumour stages were evaluated in the present study. Patients were treated either with primary tumour resection, transarterial chemoembolisation (TACE) or liver transplantation (LTx) by an interdisciplinary team. Results The overall 1-year and 5-year survivals of patients in LTx group were 95 and $57 \%$, respectively, which were significantly higher than those in primary tumour resection group (65 and 33\%, $P<0.01)$ and those in TACE group (44 and $4 \%, P<0.01)$. In parallel, 1 -year and 5 -year tumourfree survivals of patients in LTx group (75 and 62\%) were significantly higher than those in primary tumour resection group (50 and $11 \%, P<0.01$ ). There were no significant differences in 1- and 5-year survivals of patients with early tumour stage received LTx or primary tumour resection, whereas patients in advanced tumour stage based on pathological findings of explanted liver significantly benefited from LTx as compared to primary resection.
\end{abstract}

\footnotetext{
A. Obed $\cdot$ M. Obed $\cdot$ H. Becker $\cdot$ T. Lorf Department of General Surgery,

University of Göttingen Medical Centre,

Göttingen, Germany
}

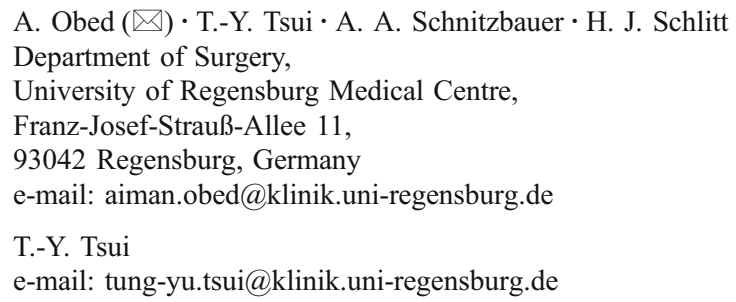

Conclusions LTx can be a curative approach for patients with advanced HCC without extrahepatic metastasis. However, organ shortage is a major limiting factor in the selection of HCC patients for LTx.

Keywords Hepatocellular carcinoma $\cdot$ Liver transplantation - Transarterial chemoembolisation . Tumour-free survival
Abbreviations
HCC hepatocellular carcinoma
TACE transarterial chemoembolisation
LTx liver transplantation

\section{Introduction}

Hepatocellular carcinoma (HCC) represents 5\% of all cancers worldwide with increasing incidence and striking differences in geographic distribution. It occurs mostly in patients with cirrhosis after high alcohol intake and/or viral hepatitis. Therapeutic approaches, either curative or palliative, include interventional and surgical therapies, like transarterial chemoembolisation (TACE), percutaneous alcohol instillation, thermoablation, primary resection and transplantation. A number of studies on the effects of TACE failed to demonstrate a beneficial effect in patient survival in comparison to conservative treatment, but it may be a therapeutic option for unresectable tumour. The role of TACE as bridging treatment for HCC before liver transplantation is still controversial. Evidence-based analysis did not show a beneficial effect of TACE as bridging therapy before liver transplantation (LTx) for HCC patients. However, the long-term effects of TACE on the tumourfree survival, particularly for the patients with advanced 
tumour stage, need to be further evaluated $[1,2]$. Primary tumour resection for HCC is limited by the size, number, location and vascular invasion of tumours. Extent of cirrhosis is also an important limiting factor for primary tumour resection that is due to the maintaining malignant potency after resection and the requirement for sufficient function in the remaining liver tissue [3-5]. Furthermore, small nodules may be overseen by radiologic and sonographic means in their potency of discriminating cirrhotic nodule from tumour. Frequently, tumour nodules are detected incidentally only in explanted livers after transplantation. In these cases, LTx remains one of the most attractive approaches for patients with $\mathrm{HCC}$ and cirrhosis. In a selected patient group following the Milan Criteria (UICC I and II), 5-year survival rate can reach more than $70 \%[3,5-7]$. On the other hand, it was shown that the UICC tumour classification system does not have prognostic power for the long-term outcome after LTx [8]. The intention of this study was to evaluate the therapeutic options for patients with advanced HCC in regards to the best therapy that is reflected by overall and tumour-free survival.

\section{Materials and methods}

\section{Patients and tumour classification}

During 1995 to 2000, 113 patients with HCC and seven patients with incidentaloma of HCC that were found after LTx were consecutively treated at the University of Göttingen Medical Centre and followed up for at least 5 years. The tumour staging was initially based on the radiological findings [computed tomography (CT) and/or magnetic resonance imaging], histological diagnosis and the pathological findings of the resected tumours or explanted livers. The diagnosed tumours were stratified into $\mathrm{HCC}$ in cirrhotic and $\mathrm{HCC}$ in non-cirrhotic livers. The cirrhotic livers were classified with the Child-Pugh-Turcotte score. Tumour stages were classified according to UICC (Union International Centre Cancer) and Milan Criteria [6] to evaluate prognostic estimation. Tumour recurrence was defined with the Barcelona Criteria as radiological findings of a focal lesion $>2 \mathrm{~cm}$ with arterial hypervascularisation and an increased alpha-fetoprotein (AFP) level $>400 \mathrm{ng} / \mathrm{ml}$ [4].

\section{Therapeutic strategies}

Patients were treated by a multidiscipline team based on their tumour stage, location and liver function with either primary resection of the tumour, TACE, LTx or LTx after bridging TACE therapy. Patients eligible for LTx were evaluated according to the German Transplantation Regulation.
TACE was performed in patients with unresectable tumours due to functional or anatomic reasons. The femoral artery was used as access vessel, and the embolisation catheter was introduced retrograde through the abdominal aorta and celiac trunk. Under suspicion of multilocular tumour growth, the whole liver was embolised even when the tumour was present in only one lobe. The liver was embolised either at a single time or alternatively one lobe first and the second lobe 2 weeks thereafter. The injected substance was a combination of $50 \mathrm{ml}$ Lipidol for a whole liver embolisation and Doxorubicin $(50 \mathrm{mg}$ for the whole liver and $25 \mathrm{mg}$ in patients with impaired liver function or portal vein thrombosis). The procedure was repeated every 6 weeks. After every two cycles, the tumour status was reevaluated by imagings.

Primary tumour resections were a primary option for patients with known HCC. They were performed by two experienced surgeons. Median laparotomy with right lateral extension was performed. Sonography of the tumor liver was performed to evaluate relation of tumour to vessels and its resectability. The tumour was then resected under Pringle maneuver with or without temporary occlusion of the suprahepatic and infrahepatic caval veins. Dissection was either performed with a Metzenbaum scissor or a water-jet device. After resection of the primary tumours, regional lymph nodes and/or the lymph nodes at the celiac trunk were resected.

HCC Patients with cirrhosis and poor liver function were considered to treat with LTx. All patients received downstaging protocol with TACE. Patients within Milan's criteria were chosen to treat with LTx. LTx was performed by the same two experienced surgeons. The transplant was either performed as a whole-organ orthotopic liver transplantation with resection of the retrohepatic caval vein or as split liver (right lobe allograft) with remaining recipient caval vein. Immunosuppressive therapy after LTx consisted of a tacrolimus-based drug regimen including corticosteroids. The corticosteroids were tapered within 3 months after transplantation. No adjuvant anti-cancer treatment was applied after surgery. During the first month after discharge, all patients were followed up weekly in the outpatient clinic. AFP assessments and abdominal ultrasound were carried out for tumour recurrence screening. Chest X-ray and abdominal CT scan were performed yearly. In case of HCC recurrence, bone scintigraphy and magnet resonance imaging was performed additionally.

\section{Histopathologic analysis}

The characteristics of HCC in resected livers and explanted liver including size, number of the tumour nodes and the micro- or macrovascular invasion of the tumour was evaluated by two pathologists. Additional information on 
Table 1 Distribution of 120 HCC patients with or without cirrhosis

\begin{tabular}{lllllll}
\hline & \multicolumn{3}{l}{ UICC Stage } & & $\begin{array}{l}\text { Gender } \\
\text { M/F }\end{array}$ & $\begin{array}{l}\text { No. of } \\
\text { patients }\end{array}$ \\
\cline { 2 - 5 } & I & II & III & IV A & & \\
\hline Cirrhosis & 5 & 13 & 14 & 45 & $66 / 8$ & 74 \\
Non-cirrhosis & 1 & 9 & 9 & 24 & $30 / 16$ & 46 \\
\hline
\end{tabular}

the influence of the tumour on the clinical course was gained from tumour-positive regional lymph nodes and the resection status. Patients were then stratified into the UICC staging system.

\section{Statistics}

Data were collected retrospectively from patient charts. Descriptive statistical analysis was performed with SigmaStat Version 3.1 (Systat Software, Richmond, CA, USA). The cumulative survival of patients was analysed with Kaplan-Meier curves and with COX regression method as indicated. Significance was defined as $P<0.05$.

\section{Results}

Demographics and tumour staging

One hundred twenty patients ( 96 men and 24 women) were included. The average age was $59 \pm 11$ years (range, 25 to 82 years). Stratified to therapeutic options the average age in patients without treatment for HCC was $63 \pm 13$ years (range, 43 to 82 years), in the TACE-group $59 \pm 10$ years (range, 35 to 79), the OLT group $52 \pm 11$ years (range, 27 to 65 years) and the resection group $61 \pm 11$ years (range, 25 to 76), revealing significant differences between the groups $(P=0.002)$. Among the patients with HCC, 74 of them (61.6\%) were accompanied with cirrhosis that was classified with the Child-Pugh-Turcotte score (Table 1). Twentyeight patients (26 men and 2 women) were in stage A, 29 patients ( 25 men and 4 women) were in stage $\mathrm{B}$, and 17 patients ( 15 men and 2 women) were in stage C. According to UICC classification, six patients were in UICC stage I (including five with cirrhosis and one without cirrhosis), 22 patients were in UICC stage II (including 13 with cirrhosis and nine without cirrhosis), 23 patients were in UICC stage III (including 14 with cirrhosis and nine without cirrhosis), and 69 patients were in UICC stage IV (including 45 with cirrhosis and 24 without cirrhosis). The stratification of patients according to UICC classifications and therapeutic options were shown in Table 2.

\section{Therapeutic options}

Ten of 120 HCC patients received only supportive therapies due to extrahepatic metastases (in three patients), protracted age and high cardiopulmonary risk (in two patients) including decease before treatment (in four patients), and refusal of treatment (in one patient). From the remaining 110 HCC patients, 47 of them had unresectable HCC, who received TACE. Thirty-six of them were primarily resected, 20 patients underwent TACE followed by LTx, and seven incidentalomas were transplanted and diagnosed as HCC thereafter (Tables 2 and 3).

The extension of liver resections consisted of single segment resections $(n=2)$, bisegemental resections $(n=5)$, left hemihepatectomies $(n=15)$, right hemihepatectomies $(n=5)$, and extended right hemihepatectomies $(n=15)$. No tumour cells were identified in the margin of all resected livers in final pathohistology.

\section{Overall survival}

All patients were followed up for at least 5 years. Median of follow-up in the non-treatment group was 72 days (range, 6 to 238 days), 200 days in TACE group (range, 16 to 2054 days), 774 days in the LTX group (range, 67 to 2,223 days), and 399 days in the resection group (range, 11 to 2,220 days). The cumulative overall survival for all patients with $\mathrm{HCC}$ in our centre after 1 and 5 years was $100 \%$ in UICC stage I, 86 and $64 \%$ in UICC stage II, 72

Table 2 Allocation of HCC patients according to the treatment strategies

\begin{tabular}{|c|c|c|c|c|c|c|c|c|}
\hline & \multirow{2}{*}{$\begin{array}{l}\text { Age } \\
\text { Mean (range) }\end{array}$} & \multirow{2}{*}{$\begin{array}{l}\text { Gender } \\
\mathrm{M} / \mathrm{F}\end{array}$} & \multicolumn{4}{|c|}{ UICC Stage } & \multirow{2}{*}{$\begin{array}{l}\text { With cirrhosis } \\
\text { No. }(\%)\end{array}$} & \multirow[t]{2}{*}{ No. of patients } \\
\hline & & & I & II & III & IV A & & \\
\hline No treatment & $63(43-82)$ & $6 / 4$ & 0 & 1 & 1 & 8 & $4(40 \%)$ & 10 \\
\hline TACE & $59(35-79)$ & $41 / 6$ & 0 & 5 & 6 & 36 & $34(72 \%)$ & 47 \\
\hline Resection & $52(25-76)$ & $26 / 10$ & 0 & 10 & 12 & 14 & $10(28 \%)$ & 36 \\
\hline TACE + LTx & $61(27-65)$ & $16 / 4$ & 2 & 5 & 4 & 9 & $20(100 \%)$ & 20 \\
\hline LTx & $61(27-65)$ & $7 / 0$ & 4 & 1 & 0 & 2 & $6(86 \%)$ & 7 \\
\hline
\end{tabular}


Table 3 Distribution of HCC patients treated with TACE and LTx

\begin{tabular}{|c|c|c|c|c|c|c|c|c|c|c|}
\hline \multirow{2}{*}{$\begin{array}{l}\text { Etiology of } \\
\text { cirrhosis }\end{array}$} & \multirow{2}{*}{$\begin{array}{l}\text { No. of } \\
\text { patients }\end{array}$} & \multirow{2}{*}{$\begin{array}{l}\text { Gender } \\
\mathrm{M} / \mathrm{F}\end{array}$} & \multicolumn{3}{|c|}{ Child-Pugh Classification } & \multirow{2}{*}{$\begin{array}{l}\text { TACE No. } \\
\text { (range) }\end{array}$} & \multicolumn{4}{|c|}{ UICC Stage (after TACE) } \\
\hline & & & $\mathrm{A}$ & B & $\mathrm{C}$ & & I & II & III & IV A \\
\hline Alcohol & 6 & $5 / 1$ & 1 & 4 & 1 & $3.5(3-6)$ & 1 & 2 & 3 & 0 \\
\hline HBV & 6 & $3 / 3$ & 3 & 2 & 1 & $3.5(2-11)$ & 1 & 2 & 0 & 3 \\
\hline $\mathrm{HCV}$ & 8 & $8 / 0$ & 3 & 4 & 1 & $2.5(2-7)$ & 0 & 1 & 2 & 5 \\
\hline
\end{tabular}

and $45 \%$ in UICC stage III, and 42 and $8 \%$ in UICC stage IVA patients $(P<0.05)$.

Stratified into the different treatment regimens after diagnosis of HCC was confirmed in final pathohistology that included all UICC stages. The survival after 1 and 5 years in patients that underwent LTx was 95 and 57\%, respectively. The 1- and 5-year survival of patients with primary resection was 65 and $33 \%$. In a group of patients treated with TACE, only $44 \%$ were alive after 1 year and $4 \%$ after 5 years. The difference between groups was highly significant $(P<0.01)$. This is reflected by the median survival times (3.8 months in the non-treated patient, 9.0 months in the TACE group, 22.8 months in the resection, and 101.6 months in the LTx group). From 27 transplanted patients, ten showed vascular macroinvasion in post-transplant pathology, which led to a significant decrease in survival after 1 and 5 years in those patients $(P=0.012$; Fig. 1).

\section{Tumour stage-based survival}

One- and 5-year patient's survival rates in UICC stage I and II were 100 and $87 \%$ in the transplant group, 100 and $80 \%$ in the resection, and 72 and $27 \%$ in the TACE group $(p=0.00003$, Tables 4 and 5). In UICC stage III, 100 and $68 \%$ of the transplant patients, 63 and $25 \%$ of the resection group, and 62 and $0 \%$ in the TACE group were alive $(p=$ 0.0006). One- and 5-year survival for UICC stage IVA revealed significant advantages for the liver transplant patients (75 and $38 \%$ in the transplant group, 38 and $0 \%$ in the resection, and 38 and $7 \%$ in the TACE group, $P=$ $0.000009)$. In the resection group, survival was significantly lower when patients had UICC stage III or IVA $(P=0.0006)$. Survival rates in the transplant group with UICC stage IVA after 1 year and with UICC stage III and IVA after 5 years was significantly lower than the remaining stages $(P=0.007$ and $P=0.0031$ for incidentalomas).

Stratification of the liver transplanted patients into Milan Criteria (UICC stage I and II) or exceeding criteria showed 17 patients within and ten patients exceeding Milan Criteria. One- and 5-year survival rates were 89 vs $62 \%$ and 75 vs $62 \%$, respectively, which showed a significant advantage for patients being within Milan Criteria $(P=$ $0.002)$. In the resection group, there was no significant difference between groups $(P=0.65)$. The data suggest that in a group of patients with HCC exceeding Milan Criteria may benefit from liver transplantation as compared with primary resection in terms of 5-year survival.
Fig. 1 Overall survival of HCC patients based on therapeutic options. $L T x$ Liver transplantation, TACE transarterial chemoembolization, Resection primary tumour resection, $T A C E+L T x$ TACE as bridging therapy

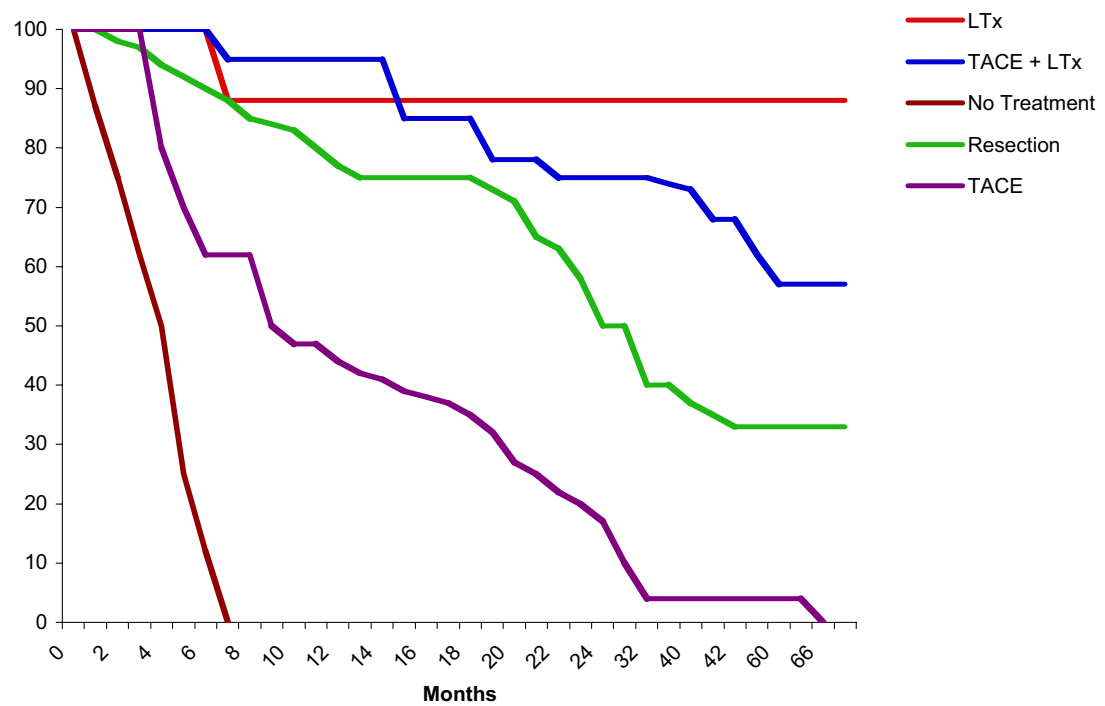


Table 4 One-year survival (\%) of HCC patients based on therapeutic options

\begin{tabular}{llll}
\hline & \multicolumn{2}{l}{ UICC Stage } & \\
\cline { 2 - 4 } & I + II & III & IV A \\
\hline TACE & 72 & 62 & 38 \\
Resection & 100 & 63 & 38 \\
LTx $^{\mathrm{a}}$ & 100 & $100^{\mathrm{b}}$ & $75^{\mathrm{b}}$ \\
\hline
\end{tabular}

${ }^{a}$ LTx represents all LTx patients including LTx alone and TACE + LTX.

${ }^{\mathrm{b}}$ Vs TACE or resection: $P<0.01$

Mortality rate after LTx and after primary tumour resection

Thirty-day mortality of the LTx group was $0 \%$. One patient died after 119 days in a septic shock. In the long term, three further patients died without relation to HCC or transplantation (one with myocardial infarct in 34 months, one with gastric bleeding in 9 months, one with esophageal cancer in 30 months). In contrast, 30-day mortality rate of the primary tumour resection group was $8.3 \%(3 / 36)$, and one patient died on day 35 after resection. Among them, two patients underwent a left hemihepatectomy, and additionally, one was combined with a pancreas head resection (who died on day 17 from myocardic infarct and on day 35 from septic shock). Another two patients received an extended right hemihepatectomy (who died on day 13 from Cor pulmonale and on day 16 from pancreatitis).

LTx is superior to primary tumour resection in terms of tumour-free survival

In the LTx group and resection group, which were considered to be treated with curative intention, tumourfree survival after 1 and 5 years was 75 and $72 \%$ for patients in the LTx group vs 50 and $11 \%$ in the resection group (Fig. 2). Patients significantly benefited from liver transplantation compared to primary resection in terms of

Table 5 Five-year survival (\%) of HCC patients based on tumor stage and therapeutic options

\begin{tabular}{llll}
\hline & \multicolumn{2}{l}{ UICC Stage } & \\
\cline { 2 - 4 } & I + II & III & IV A \\
\hline TACE & 27 & 0 & 4 \\
Resection & 80 & 25 & 0 \\
LTx $^{\text {a }}$ & 87 & $68^{\mathrm{b}}$ & $38^{\mathrm{b}}$ \\
\hline
\end{tabular}

${ }^{a}$ LTx represents all LTx patients including LTx alone and TACE + LTX.

${ }^{\mathrm{b}}$ Vs TACE or resection: $P<0.01$ tumour-free survival $(P=0.005)$. Stratification of the LTx patients again into Milan Criteria or exceeding criteria showed 17 patients within and ten patients exceeding criteria. One- and 5-year recurrence-free survival rates were 89 vs $62 \%$ and 75 vs $62 \%$, respectively. This suggests a significant advantage for patients being within Milan Criteria in 1-year tumour-free survival $(P=0.002)$, whereas there was no significant difference in 5 -year tumour-free survival. In the resection group, there was no significant difference between groups $(P=0.65)$.

\section{Discussion}

Based on the present analysis of a single centre data, liver transplantation represents the best curative approach in the treatment of patients with HCC. Data on TACE show 1 -year overall survival rates of $21 \%$ [9], $24 \%$ and $51 \%$ [10], $82 \%$ [8], and $57 \%$ [11] in comparison to $44 \%$ in our collective data, which is consistent. Efficacy of TACE with complete tumour response is $0-4.8 \%$, and thus, very rare, as variable tumour cells remain after the procedure. Consequently, only patients with a stop in tumour progress really do benefit from TACE in the long term. It can be achieved by the LTx [12, 13]. Our data on surgical resection show 77 and $32 \%$ in 1- and 5-year survival rates, respectively, which comparable is with the data in literature showing 1-year survival rate ranging from 44 to $100 \%$ and 5 -year survival rate ranging from 32 to $93 \%$ [14-19]. Ikai et al. [19] give different survival rates after resection in dependence from tumour size. One- and 5-year survival after resection of small HCC $(2.1-5 \mathrm{~cm}$ in diameter) is 70 and $53 \%$ vs large HCC $(5.1-10 \mathrm{~cm}$ in diameter) of 53 and $37 \%$. In our collective UICC, stages II and III include tumours of the same size, and survival rates after 1 and 5 years are 100 and $80 \%$ in stage II and 63 and $25 \%$ in stage III. Finally, data on LTx are absolutely consistent with our findings, and survival rates after 1 year ranging from 80 to $90 \%$ as compared to $95 \%$ in our series, and after 5 years ranging from 61 to $75 \%$ as compared to $57 \%$ in our series $[1,3,6,7,20]$.

Patients may still benefit from LTx even if they suffer from an $\mathrm{HCC}$ in an advanced stage. Our data show that survival rates are significantly better within each single UICC stage, in particular in advanced stages, for LTx than for resection and TACE-treated patients. TACE can be an adjuvant, rarely curative, therapeutic approach [21]. Patients often receive TACE as a bridging therapy to LTx in our centre. However, its role still has to be evaluated in a randomised control trial. Nevertheless, TACE can be an option of treatment for the patients being in the waiting list to reduce the high mortality rate before they get an offer for LTx. 
Fig. 2 Tumour-free survival of HCC patients based on curative therapies. LTx represents all LTx patients including LTx alone and TACE + LTx

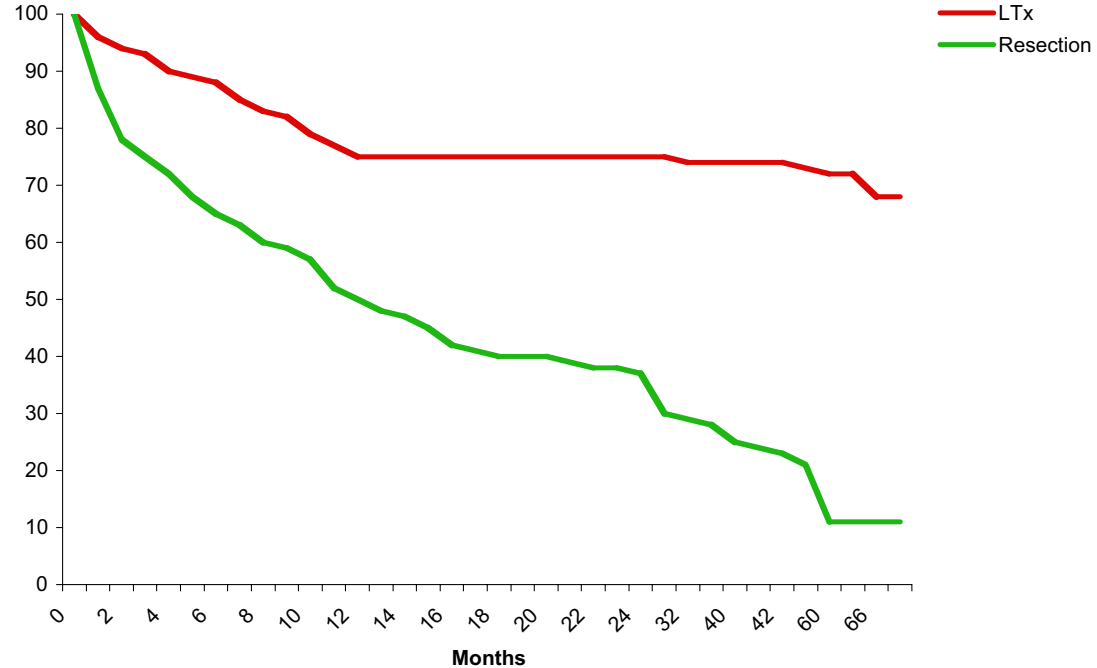

Tumour-free survival in our LTx data containing all UICC stages was 75 and $72 \%$ after 1 and 5 years, which is significantly better than in the resection group. Stratification into Milan Criteria and exceeding criteria revealed 1 - and 5-year tumour-free survival rates of 89 and $62 \%$. Data from literature show similar results in tumour-free survival of approximately 90 and $70-80 \%$ after 1 and 5 years $[6,22]$. Nevertheless, there are fine differences of tumour-free survival within the LTx group. Pathohistology of micro- and macroangioinvasive tumor growth decreased overall and tumour-free survival in the LTx group significantly. This observation is consistent with data in literature. Figueras et al. [23] showed macrovascular invasion to be an independent risk factor for mortality and recurrence. Actually, all ten patients in our series with angioinvasive tumor growth had a significant drop in the median survival and tumour-free survival. It may suggest that the vascular invasion can still be a risk factor for the tumour recurrence after transplantation.

Interestingly, the stratification of surgery proceeded patients into Milan and exceeding criteria did not impact the tumour-free survival, which can probably be explained by remnants of tumour or additional non-detected tumour nodes in cirrhotic tissue, which occasionally presents as incidentalomas after LTx $[24,25]$. In comparison to other kinds of treatment, LTx remains the best therapeutic option for HCC in our series.

The mortalities after primary tumour resection and after LTx in our series are comparable. Outcome of primary tumour resection depends on various factors. Patients with impaired liver function (mainly suffering from cirrhosis Child B-C) face the problem of the function of remaining cirrhotic liver with potential risks of increasing mortality and morbidity after the procedure. The treatment of choice in non-cirrhotic patients remains resection, and it can be performed with less life-threatening complications [8]. Indeed, two of three mortal cases within the first 30 days after surgery in our series had cirrhosis. The surgical refinement and standardisation of the procedure of LTx may make it comparable to large liver resection in terms of complications and mortality.

In conclusion, LTx can be a curative approach for HCC patient in all tumour stages without extrahepatic metastases, as compared to alternative conservative, interventional or other surgical therapies. This concept should be further proved by a prospective study. Based on the data of present study, all HCC patients without extrahepatic metastases could be potentially placed onto waiting lists for liver transplantation. This will dramatically increase the organ shortage. A refinement of selection criteria (or refinement of extended Milan criteria) is currently needed to benefit all patients with HCC or with end-stage liver diseases. Future approaches to further improvement in overall and tumourfree survival in LTx patients with primary disease of HCC should focus on two major subjects. First, due to organ shortage, priority should be given to patients within Milan criteria vs those exceeding criteria in the same MELD score. Second, individualisation of immunosuppression in patients with $\mathrm{HCC}$ is recommended. As the commonly used immunosuppressant drugs, like calcineurin inhibitors, have potential disadvantages in the prevention of tumour recurrence, there is a requirement for substances that can provide adequate immunosuppressive effects and can suppress tumour recurrence in the recipient. A group of mTOR inhibitors are likely to have this potential, but their probable and singularly observed beneficial effect on the recurrence of HCC after LTx must be evaluated in a prospectively randomised study. 


\section{References}

1. Yao FY, Kinkhabwala M, LaBerge JM, Bass NM, Brown R Jr, Kerlan R, Venook A, Ascher NL, Emond JC, Roberts JP (2005) The impact of pre-operative loco-regional therapy on outcome after liver transplantation for hepatocellular carcinoma. Am J Transplant 5(4 Pt 1):795-804, (Apr)

2. Oldhafer KJ, Chavan A, Fruhauf NR, Flemming P, Schlitt HJ, Kubicka S, Nashan B, Weimann A, Raab R, Manns MP, Galanski M (1998) Arterial chemoembolization before liver transplantation in patients with hepatocellular carcinoma: marked tumor necrosis, but no survival benefit? J Hepatol 29(6):953-959, (Dec)

3. Bismuth H, Chiche L, Adam R, Castaing D, Diamond T, Dennison A (1993) Liver resection versus transplantation for hepatocellular carcinoma in cirrhotic patients. Ann Surg 218 (2):145-151, (Aug)

4. Bruix J, Sherman M, Llovet JM, Beaugrand M, Lencioni R, Burroughs AK, Christensen E, Pagliaro L, Colombo M, Rodes J (2001) EASL Panel of Experts on HCC. Clinical management of hepatocellular carcinoma. Conclusions of the Barcelona-2000 EASL Conference. European Association for the Study of the Liver. J Hepatol 35(3):421-430, (Sep)

5. Llovet JM, Fuster J, Bruix J (1999) Intention-to-treat analysis of surgical treatment for early hepatocellular carcinoma: resection versus transplantation. Hepatology 30(6):1434-1440, (Dec)

6. Mazzaferro V, Regalia E, Doci R, Andreola S, Pulvirenti A, Bozzetti F, Montalto F, Ammatuna M, Morabito A, Gennari L (1996) Liver transplantation for the treatment of small hepatocellular carcinomas in patients with cirrhosis. N Engl J Med 334 (11):693-699, (Mar 14)

7. Jonas S, Bechstein WO, Steinmuller T, Herrmann M, Radke C, Berg T, Settmacher U, Neuhaus P (2001) Vascular invasion and histopathologic grading determine outcome after liver transplantation for hepatocellular carcinoma in cirrhosis. Hepatology 33 (5):1080-1086, (May)

8. Llovet JM, Bruix J, Fuster J, Castells A, Garcia-Valdecasas JC, Grande L, Franca A, Bru C, Navasa M, Ayuso MC, Sole M, Real MI, Vilana R, Rimola A, Visa J, Rodes J (1998) Liver transplantation for small hepatocellular carcinoma: the tumornode-metastasis classification does not have prognostic power. Hepatology 27(6):1572-1577, (Jun)

9. Lin CS, Jen YM, Chiu SY, Hwang JM, Chao HL, Lin HY, Shum WY (2006) Treatment of portal vein tumor thrombosis of hepatoma patients with either stereotactic radiotherapy or three dimensional conformal radiotherapy. Jpn J Clin Oncol 36(4):212217, (Apr)

10. Pelletier G, Ducreux M, Gay F, Luboinski M, Hagege H, Dao T, Van Steenbergen W, Buffet C, Rougier P, Adler M, Pignon JP, Roche A (1998) Treatment of unresectable hepatocellular carcinoma with lipiodol chemoembolization: a multicenter randomized trial. Groupe CHC. J Hepatol 29(1):129-134, (Jul)

11. Lo CM, Ngan H, Tso WK, Liu CL, Lam CM, Poon RT, Fan ST, Wong J (2002) Randomized controlled trial of transarterial lipiodol chemoembolization for unresectable hepatocellular carcinoma. Hepatology 35(5):1164-1171, (May)

12. Jansen MC, van Hillegersberg R, Chamuleau RA, van Delden OM, Gouma DJ, van Gulik TM (2005) Outcome of regional and local ablative therapies for hepatocellular carcinoma: a collective review. Eur J Surg Oncol 31(4):331-347, (May)

13. Otto G, Herber S, Heise M, Lohse AW, Monch C, Bittinger F, Hoppe-Lotichius M, Schuchmann M, Victor A, Pitton M (2006) Response to transarterial chemoembolization as a biological selection criterion for liver transplantation in hepatocellular carcinoma. Liver Transplant 12(8):1260-1267, (Aug)

14. Little SA, Fong Y (2001) Hepatocellular carcinoma: current surgical management. Semin Oncol 28(5):474-486, (Oct)

15. Arii S, Yamaoka Y, Futagawa S, Inoue K, Kobayashi K, Kojiro M, Makuuchi M, Nakamura Y, Okita K, Yamada R (2000) Results of surgical and nonsurgical treatment for small-sized hepatocellular carcinomas: a retrospective and nationwide survey in Japan. The Liver Cancer Study Group of Japan. Hepatology 32(6):12241229 , (Dec)

16. Zhou XD, Tang ZY (1997) Management of hepatocellular carcinoma: long-term outcome in 2639 cases. Gan To Kagaku Ryoho 24(Suppl 1):9-16, (May)

17. Poon RT, Fan ST (2004) Hepatectomy for hepatocellular carcinoma: patient selection and postoperative outcome. Liver Transplant 10(2 Suppl 1):S39-S45, (Feb)

18. Wayne JD, Lauwers GY, Ikai I, Doherty DA, Belghiti J, Yamaoka Y, Regimbeau JM, Nagorney DM, Do KA, Ellis LM, Curley SA, Pollock RE, Vauthey JN (2002) Preoperative predictors of survival after resection of small hepatocellular carcinomas. Ann Surg 235(5):722-730, (May)

19. Ikai I, Arii S, Kojiro M, Ichida T, Makuuchi M, Matsuyama Y, Nakanuma Y, Okita K, Omata M, Takayasu K, Yamaoka Y (2004) Reevaluation of prognostic factors for survival after liver resection in patients with hepatocellular carcinoma in a Japanese nationwide survey. Cancer 101(4):796-802, (Aug 15)

20. Adam R, Azoulay D, Castaing D, Eshkenazy R, Pascal G, Hashizume K, Samuel D, Bismuth H (2003) Liver resection as a bridge to transplantation for hepatocellular carcinoma on cirrhosis: a reasonable strategy? Ann Surg 238(4):508-518, (Oct)

21. Lubienski A (2005) Hepatocellular carcinoma: interventional bridging to liver transplantation. Transplantation 80 (1 Suppl): S113-S119, (Sep 27)

22. Bechstein WO, Guckelberger O, Kling N, Rayes N, Tullius SG, Lobeck H, Vogl T, Jonas S, Neuhaus P (1998) Recurrence-free survival after liver transplantation for small hepatocellular carcinoma. Transpl Int 11(Suppl 1):S189-S192

23. Figueras J, Ibanez L, Ramos E, Jaurrieta E, Ortiz-de-Urbina J, Pardo F, Mir J, Loinaz C, Herrera L, Lopez-Cillero P, Santoyo J (2001) Selection criteria for liver transplantation in early-stage hepatocellular carcinoma with cirrhosis: results of a multicenter study. Liver Transplant 7(10):877-883, (Oct)

24. Baccarani U, Adani GL, Avellini C, Lorenzin D, Curro G, Beltrami A, Pasqualucci A, Bresadola V, Risaliti A, Viale PL, Beltrami CA, Bresadola F (2006) Comparison of clinical and pathological staging and long-term results of liver transplantation for hepatocellular carcinoma in a single transplant center. Transplant Proc 38(4):1111-1113, (May)

25. Schlitt HJ, Neipp M, Weimann A, Oldhafer KJ, Schmoll E, Boeker K, Nashan B, Kubicka S, Maschek H, Tusch G, Raab R, Ringe B, Manns MP, Pichlmayr R (1999) Recurrence patterns of hepatocellular and fibrolamellar carcinoma after liver transplantation. J Clin Oncol 17(1):324-331, (Jan) 